\title{
BMJ Open Experiences of Venous Leg Ulcer persons following an individualised nurse-led education: protocol for a qualitative study using a constructivist grounded theory approach
}

\author{
Paul Bobbink (D) , ${ }^{1,2}$ Philip J Larkin, ${ }^{3}$ Sebastian Probst (D) ${ }^{1}$
}

To cite: Bobbink P, Larkin PJ, Probst S. Experiences of Venous Leg Ulcer persons following an individualised nurse-led education: protocol for a qualitative study using a constructivist grounded theory approach. BMJ Open 2020;10:e042605. doi:10.1136/ bmjopen-2020-042605

- Prepublication history and additional material for this paper are available online. To view these files, please visit the journal online (http://dx.doi. org/10.1136/bmjopen-2020042605).

Received 11 July 2020 Revised 17 September 2020 Accepted 03 November 2020

Check for updates

(c) Author(s) (or their employer(s)) 2020. Re-use permitted under CC BY-NC. No commercial re-use. See rights and permissions. Published by BMJ.

${ }^{1}$ HES-SO, University of Applied Sciences and Arts Western Switzerland, Geneva School of Health Sciences, Geneva, Switzerland

${ }^{2}$ University Institute of Higher Education and Research in Healthcare, Faculty of Biology and Medicine, University of Lausanne, Lausanne, Switzerland

${ }^{3}$ University of Lausanne and University Hospital Lausanne, Lausanne, Switzerland

Correspondence to

Paul Bobbink;

paul.bobbink@hesge.ch

\section{ABSTRACT}

Introduction Venous leg ulcers are slow-healing wounds with a high risk of recurrences. To prevent recurrences and promote healing, different nurse-led educational interventions have been developed. The impact of these interventions on self-management is ambiguous. Also, how persons with a venous leg ulcer experiences these educational sessions are poorly described.

Aim This study protocol presents the methodology to provide a comprehensive explanation of participants' journeys - of how they experience their individualised education sessions concerning self-management. Methods and analysis A constructivist grounded theory approach according to Charmaz involving 30 participants will be used. Data will be collected through semistructured face-to-face interviews. Interviews will be transcribed verbatim and analysed with initial and focus coding using MAXQDA. Data collection and data analysis will occur iteratively, focusing on constant comparison to obtain welldeveloped categories. Categories will be reinforced using existent literature.

Ethics and dissemination This pre-results study is embedded in a clinical trial (NCT04019340) and approved by ethical committee of the canton of Geneva (CCER: 2019-01964). A theory will emerge from participants' journeys informing future education sessions for patients with venous leg ulcers. The findings will be disseminated through peer-reviewed publications and communications.

\section{INTRODUCTION}

Venous leg ulcers (VLUs) are defined as a loss of skin on the lower leg or foot taking more than 6 weeks to heal. ${ }^{1}$ They are the most frequent aetiology of leg ulcer $(70 \%)$ and are associated with chronic venous insufficiency. ${ }^{2}$ The estimated prevalence of VLUs is approximately $0.9 \%$ of the global population, ${ }^{34}$ is higher in women ${ }^{4}$ and rises above $2 \%$ in the population aged $>85$ years. ${ }^{4-6}$ Management of VLUs is costly. In the UK, annual costs associated with VLUs are estimated at $\$ 941$ million. ${ }^{7}$ All these numbers will increase over the next years due to the ageing of the population. ${ }^{8}$
Strengths and limitations of this study

- This study protocol demonstrates how a constructivist grounded theory approach highlights patients voices.

- A systematic and iterative approach with constant comparative analysis will enable the refinement of relevant categories.

- The results of the study will be a production of inductively derived generalisations about patients with venous leg ulcer following a standardised education programme.

- Theoretical sampling is challenging for a grounded theory study protocol.

VLUs are slow-healing wounds as only $53 \%$ of VLUs heal within 1 year. ${ }^{9}$ Once healed, they are associated with a high recurrence rate estimated at $39 \%$ at 6 months and $57 \%$ at 1 year. ${ }^{10}$ Persons with VLUs experience symptoms including pain, insomnia, exudate and odour. ${ }^{11}$ Qualitative data identified pain as the worst symptom and described it as burning, shooting or itching. ${ }^{12}$ Moreover, up to $64 \%$ of persons with VLUs will experience four or more symptoms at the same time. ${ }^{13}$

Persons with VLUs have to cope with other chronic conditions such as hypertension, musculoskeletal disease or atrial fibrillation, which are frequently $(90 \%)$ associated with VLUs. ${ }^{14}$ This complex situation has a big impact on quality of life ${ }^{15}$ and provides challenges for individuals when managing their multiple diseases.

The gold standard used to enhance healing and prevent VLU recurrence is compression therapy. ${ }^{16}$ Heyer et $a l^{17}$ stated that only $40.6 \%$ of patients with VLU received compression therapy. Non-adherence to therapy is frequently described in this population. ${ }^{18} 19$ 
Reasons for non-adherence are multidimensional, ${ }^{20}$ including discomfort and pain associated with compression therapy ${ }^{21} 22$ or conflicting advises by healthcare professionals, ${ }^{23}$ and frequently lead back to misunderstanding the underlying causes of their VLUs ${ }^{24} 25$ or the benefits of self-care activities such as walking or resting in an optimal position. ${ }^{26}$ Knowledge deficit is a frequent hypotheses for why chronic venous disease develops into a first VLU ${ }^{27}$ or a recurrence. ${ }^{28}$ Conversely, adherence to compression therapy improves with participants' knowledge level. ${ }^{29}$

To address knowledge deficit, promote healing and prevent VLU, patient-education has to be multifaceted and oriented towards protective factors intended to prevent recurrence. This includes increasing knowledge about their disease and skills such as why and how to wear compression stockings ${ }^{16} 3031$ and promoting mobility, ${ }^{32}$ leg elevation, walking, and ankle and foot exercises, ${ }^{33}{ }^{34}$ as well as the benefits of micronutrients including a vitaminrich diet. ${ }^{35}$ Providing written materials such as brochures for patients with VLU could improve their knowledge. ${ }^{36}$ Protz et $a l^{36}$ suggest that written information must be used in an educational setting in which patients have the opportunity to ask questions. When they arise, nurses mostly respond to these questions as they provide most of the wound care interventions. ${ }^{79}$ Moreover, nurses have developed multiple individualised patient education programmes. ${ }^{37-42}$

However, different systematic reviews ${ }^{31} 43$ reveal a lack of high-quality randomised controlled trials (RCTs) that address the effectiveness of these interventions on adherence to therapy or wound healing. For this reason, Probst et $a l^{445}$ developed an interprofessional educational intervention to promote wound healing and self-management strategies. This individualised nurse-led education programme will start with face-to-face meetings between a tissue viability nurse and participants. During the first meeting, the study nurse will provide an evidence-based brochure. This first step of the educational process will provide participants with an opportunity to learn about various aspects of their disease and receive evidencebased recommendations for individualised treatment. To evaluate the effectiveness of this intervention, an RCT design with 124 participants will be used. ${ }^{45}$ However, these results will not provide information about the process and the reasons for its effectiveness. ${ }^{37}$

Van Hecke $e t a l^{37}$ described cognitive changes associated with understanding what lifestyle adaptations to implement and why, as well as implementing behaviour changes through creative lifestyle and emotional efforts associated with gaining hope and a new perspective. Learning and implementing change is not a simple task for patients. Moreover, the intervention itself, its context, the environment and conditions can affect the learning process. ${ }^{46}$ The nurse-patient relationship is important in face-to-face educational sessions. Phillips $e t$ $a l^{2}$ reviewed contradictory data and revealed that good communication was perceived positively. In fact, a good communication and a trusting relationship seem to promote compliance. ${ }^{47}$

However, nothing is known about how patients with VLUs experience nurse-led educational programmes and implement lifestyle changes.

\section{AIMS AND OBJECTIVES}

This study aims to develop a comprehensive contextualised explanation of how patients with VLU experience an individualised patient education programme regarding self-management of VLUs (hereafter their journey).

The study's objectives are as follows:

1. Qualitatively map journeys.

2. Identify self-management strategies and decisions within these journeys.

3 . Identify the contextual and personal perception of behaviour change shaping their journey

4. Provide a comprehensive explanation of the participants' experiences/process of individualised educational session.

\section{METHOD}

A grounded theory (GT) is best suited to investigate a process, interactions between individuals or journeys through an illness condition. ${ }^{48}$ GTs are used in health and social sciences to generate theoretical accounts of psychosocial processes. ${ }^{49}$ However, philosophical perspectives of GTs varied across authors. ${ }^{50}$ To provide a congruent method between the principal investigator and the research field, a constructivist grounded theory $(\mathrm{CGT})^{51}{ }^{52}$ was chosen. This inductive approach is widely used in nursing and allows for exploring the process of patient education. It takes into consideration the concerns of participants who are involved in the process and the researcher's preliminary knowledge and experiences about the clinical field. According to the PhD project, a preliminary literature review and scoping review $^{53}$ were conducted to expose the gap of existent knowledge. These preliminary reviews are congruent with a CGT methodology to reveal how this subject has been addressed previously ${ }^{54}$ and could be engaged critically and comparatively in the process. ${ }^{52}$ CGT offers researchers the ability to provide interpretative aspects and to co-construct the research via the shared experiences of the researcher, participants and readers. ${ }^{455}$

\section{STUDY TEAM}

This study protocol is a $\mathrm{PhD}$ project from $\mathrm{PB}$, a novice qualitative researcher, that is embedded within a larger trial (Clinical Trial Number: NCT04019340). The research team consists of two senior researchers: one (SP) with expertise in VLUs, patient education and qualitative designs, and another (PJL) with expertise in methodology for qualitative designs. 


\section{STUDY SETTING}

This multicentre study will be conducted in three outpatient wound care clinics in the French-speaking part of Switzerland.

\section{Participants and recruitment}

Participants from the RCT intervention group will be eligible for this study when they have followed five individualised education sessions. The following inclusion criteria will be applied: an existing open VLU, an ankle brachial pressure index between 0.8 and 1.3, aged $>18$ years and proficiency in French language. Participants will be excluded for not providing consent. ${ }^{45}$ After participants complete five individualised education sessions, the intervention study nurse will inform them that $\mathrm{PB}$ will contact them to organise an interview.

In GT, the use of theoretical sampling enables welldeveloped, defined and delimited categories to be obtained. ${ }^{56}$ However, this method contends that it is not possible to know the precise sample size in advance. ${ }^{52}$ Theoretical sampling is ambiguously used or described in published GT $^{57}$ In CGT, the sample size is determined on the basis of credibility, context and inquiry purpose..$^{51} 52$ Evidence demonstrates sample sizes ranging from 20 to 35 participants. ${ }^{55} 58$ Taking into consideration the study's aim, the skills of the interviewer and the extant literature, we expect that 30 participants will provide rich data for an initial sample.

\section{Patient and public involvement}

This is a study protocol for a CGT method, and therefore no patients or consumer's groups are yet involved.

\section{Data collection}

PB will collect data using semistructured interviews. This approach encourages articulation of experiences and views of the participants. We have developed initial openended questions based on our clinical experience, the scope of the intervention and a literature review. These provide the openness necessary to obtain a broader overview of the field of investigation and listen to participants recounting their journey. ${ }^{52}$ Box 1 lists some initial questions translated from French. Charmaz ${ }^{52}$ describes intensive interviewing as a method suited for the flexibility and adaptability of CGT and the field of inquiry. It

\section{Box 1 Initial questions translated from French to English}

You followed five consultations with a tissue viability nurse. What was your experience of these consultations?

What was your experience of these meetings in terms of care and treatment?

- Could you describe what it changed in your day?

- Tell me, how do these sessions influence your journey living with venous leg ulcer (VLU)?

What has been most helpful during this process?

- After your experiences, what would you recommend to people with VLUs? permits data collection adjustments directly during interview as well as during the iterative data collection and analysis process. ${ }^{52}$ The interviews were initially planned to take place according to participants' preferences at their home or the outpatient clinic. However, due to the COVID-19 outbreak in our country, data collection began via telephone call or videoconference to preserve participants' safety and maintain the study period. Ward et a $\bar{\rho}^{9}$ described the use of telephone interviews as congruent with GT with some strengths, as participants reported feeling more relaxed or not feeling judged for their comments. Reported inconveniences included that telephone interviews did not offer the possibility to observe non-verbal behaviours. The interviews are planned for 45-60 min. If participants agree, the interviews will be recorded digitally for verbatim text transcription. Data collection started in April 2020 and is planned for 12 months.

\section{Data management}

All data will be saved on a secured, password-protected server at the HES-SO University of Applied Sciences and Arts, Geneva. Only the investigators will have access to the data. In addition, data will be deidentified and archived on the Geneva YARETA portal, ${ }^{60}$ which meets Findable Accessible Interoperable Reusable (FAIR) requirements. Sociodemographic data will be analysed using IBM SPSS V.25. $0^{61}$ for descriptive statistics. After verbatim transcription and anonymisation of the data, participants will be assigned pseudonyms.

\section{Data analysis}

MAXQDA $^{62}$ will be used to assist qualitative data analysis. According to Charmaz, ${ }^{52}$ coding will be performed using two steps: (1) initial coding process using line-by-line coding to label these fragments with codes and (2) focus coding using codes that recur frequently and seem to be most relevant. These codes include data interpretation, and with further analysis indentify relationships between categories and their orientation on theroretical development. ${ }^{49} 5255$ This systematic and iterative approach with constant comparative analysis of data with data or data with categories will permit refinement of relevant categories during the data collection process. To engage in the analytical process, define links between $\operatorname{codes}^{52}$ and enhance reflexivity on the process, ${ }^{63}$ memo writing will be used. This process will be documented in a 'memo bank' stored in MAXQDA. ${ }^{62}$ Software-assisted analysis will allow for transparent analysis ${ }^{49}$ even if it could take the researcher 'away' from his data and lead to a 'mechanical activity' in place of a cognitive process. ${ }^{55}$ To improve the process, data analysis will be supervised by SP and PJL.

\section{Quality criteria and expected outcomes}

GT evaluation criteria depend on the approach. ${ }^{63}$ Charmaz $^{52}$ defined criteria for quality as credibility, resonance, originality and usefulness. Credibility will be assumed based on the scope and depths of the interviews 
and the quality of the iterative process to obtain links between data and categories. Resonance will, first, be discussed during intensive interviewing with participants to obtain well-developed categories and, second, when sharing the outcomes with persons involved in the patient education process and during literature reviews aiming to extend and challenge theoretical development. ${ }^{52}$ Finally, as this is a PhD thesis and the data are collected via person's experiences, interactions and existent literature, we hope that this project will provide a well-developed theory that includes refined concepts to better understand patient experiences and the development of clinical practices regarding the outcomes.

\section{Ethics and dissemination}

The ethics committee of canton of Geneva approved this study (CCER: 2019-01964). All participants will receive an informational document and a consent form detailing the objectives of the study, the procedures involved, insurance and data confidentiality. All participants must provide their written consent prior to data collection.

This is the first study focusing on the process of how participants experience an individualised patient education programme related to self-management. Supervision by senior researchers for method and rigour during the process will allow this project to propose an image of a reality that will be co-created between the research team, participants and actual knowledge. Outcomes will be disseminated via publication papers, oral presentations or posters to provide a new insight and support VLU patient education. Quality of the publications will be ensured using GUidelines for REporting GT research studies (GUREGT). ${ }^{64}$

Contributors PB designed the study and wrote the initial manuscript. SP originated the concept of the project, supervised the design and acquired the funding. PJL provided support for design. PB, PJL and SP contributed to writing or reviewing the manuscript. All authors revised the manuscript and approved the final version to be published.

Funding This work is part of a PhD project funded by the Swiss National Sciences Foundation (SNF; number: 10531C_185332) and supported by the HES-S0 University of Applied Sciences and Arts Western Switzerland, Geneva, Switzerland.

\section{Competing interests None declared.}

Patient and public involvement Patients and/or the public were not involved in the design, or conduct, or reporting, or dissemination plans of this research.

\section{Patient consent for publication Not required.}

Provenance and peer review Not commissioned; externally peer reviewed.

Open access This is an open access article distributed in accordance with the Creative Commons Attribution Non Commercial (CC BY-NC 4.0) license, which permits others to distribute, remix, adapt, build upon this work non-commercially, and license their derivative works on different terms, provided the original work is properly cited, appropriate credit is given, any changes made indicated, and the use is non-commercial. See: http://creativecommons.org/licenses/by-nc/4.0/.

\section{ORCID iDs}

Paul Bobbink http://orcid.org/0000-0001-6407-455X

Sebastian Probst http://orcid.org/0000-0001-9603-1570
2 Poskitt KR, Gohel MS. Chronic ulceration of the leg. Surgery 2016;34:178-82 https://doi.org/

3 Nussbaum SR, Carter MJ, Fife CE, et al. An economic evaluation of the impact, cost, and Medicare policy implications of chronic nonhealing wounds. Value Health 2018;21:27-32 https://doi.org/

4 Kreft D, Keiler J, Grambow E, et al. Prevalence and mortality of venous leg diseases of the deep veins: an observational cohort study based on German health claims data. Angiology 2020;71:452-64 https://doi.org/

5 Heyer K, Herberger K, Protz K, et al. Epidemiology of chronic wounds in Germany: analysis of statutory health insurance data. Wound Repair Regen 2016;24:434-42 https://doi.org/

6 Berenguer Pérez M, López-Casanova P, Sarabia Lavín R, et al. Epidemiology of venous leg ulcers in primary health care: incidence and prevalence in a health centre-A time series study (2010-2014). Int Wound J 2019;16:256-65 https://doi.org/

7 Guest JF, Ayoub N, Mcllwraith T, et al. Health economic burden that different wound types impose on the UK's National health service. Int Wound J 2017;14:322-30 https://doi.org/

8 (FSO) FSO. Population trends from 2020 to 2050: growth, ageing and concentration around large towns, 2020. Available: https://www.

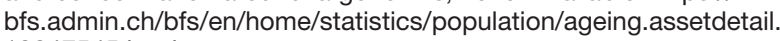
12847545.html

9 Guest JF, Fuller GW, Vowden P. Venous leg ulcer management in clinical practice in the UK: costs and outcomes. Int Wound $J$ 2018;15:29-37 https://doi.org/

10 Finlayson K, Wu M-L, Edwards HE. Identifying risk factors and protective factors for venous leg ulcer recurrence using a theoretical approach: a longitudinal study. Int J Nurs Stud 2015;52:1042-51 https://doi.org/

11 Heinen MM, Persoon A, van de Kerkhof $P$, et al. Ulcer-Related problems and health care needs in patients with venous leg ulceration: a descriptive, cross-sectional study. Int J Nurs Stud 2007:44:1296-303 https://doi.org/

12 Phillips P, Lumley E, Duncan R, et al. A systematic review of qualitative research into people's experiences of living with venous leg ulcers. J Adv Nurs 2018;74:550-63 https://doi.org/

13 Edwards $\mathrm{H}$, Finlayson K, Skerman $\mathrm{H}$, et al. Identification of symptom clusters in patients with chronic venous leg ulcers. J Pain Symptom Manage 2014;47:867-75 https://doi.org/

14 Kelly M, Gethin G. Prevalence of chronic illness and risk factors for chronic illness among patients with venous leg ulceration: a crosssectional study. Int J Low Extrem Wounds 2019;18:301-8 https://doi. org/

15 Herber OR, Schnepp W, Rieger MA. A systematic review on the impact of leg ulceration on patients' quality of life. Health Qual Life Outcomes 2007;5:44 https://doi.org/

16 O'Meara S, Cullum N, Nelson EA, et al. Compression for venous leg ulcers. Cochrane Database Syst Rev 2012;11:CD000265 https://doi. org/

17 Heyer K, Protz K, Augustin M. Compression therapy - cross-sectional observational survey about knowledge and practical treatment of specialised and non-specialised nurses and therapists. Int Wound $J$ 2017;14:1148-53 https://doi.org/

18 Heinen MM, van der Vleuten C, de Rooij MJM, et al. Physical activity and adherence to compression therapy in patients with venous leg ulcers. Arch Dermatol 2007;143:1283-8 https://doi.org/

19 Raju S, Hollis K, Neglen P. Use of compression stockings in chronic venous disease: patient compliance and efficacy. Ann Vasc Surg 2007;21:790-5 https://doi.org/

20 Van Hecke A, Grypdonck M, Defloor T. A review of why patients with leg ulcers do not adhere to treatment. J Clin Nurs 2009;18:337-49 https://doi.org/

21 Douglas V. Living with a chronic leg ulcer: an insight into patients experiences and feelings. $J$ Wound Care 2001;10:355-60 https://doi. org/

22 Briggs M, Closs SJ. Patients' perceptions of the impact of treatments and products on their experience of leg ulcer pain. $J$ Wound Care 2006;15:333-7 https://doi.org/

23 Mudge E, Holloway S, Simmonds W, et al. Living with venous leg ulceration: issues concerning adherence. Br J Nurs 2006;15:1166-71 https://doi.org/

24 Van Hecke A, Beeckman D, Grypdonck M, et al. Knowledge deficits and information-seeking behavior in leg ulcer patients: an exploratory qualitative study. J Wound Ostomy Continence Nurs 2013;40:381-7 https://doi.org/

25 Edwards LM, Moffatt CJ, Franks PJ. An exploration of patients' understanding of leg ulceration. J Wound Care 2002;11:35-9 https:// doi.org/

\section{REFERENCES}

1 Nelson EA. Venous leg ulcers. BMJ Clinical Evidence 2011:2011. 
26 Chase SK, Whittemore R, Crosby N, et al. Living with chronic venous leg ulcers: a descriptive study of knowledge and functional health status. J Community Health Nurs 2000;17:1-13 https://doi.org/

27 Meulendijks AM, Welbie M, Tjin EPM, et al. A qualitative study on the patient's narrative in the progression of chronic venous disease into a first venous leg ulcer: a series of events. Br J Dermatol 2020;183:332-9 https://doi.org/

28 Probst S, Séchaud L, Bobbink P, et al. The lived experience of recurrence prevention in patients with venous leg ulcers: an interpretative phenomenological study. J Tissue Viability 2020;29:176-9 https://doi.org/

29 Finlayson K, Edwards H, Courtney M. The impact of psychosocial factors on adherence to compression therapy to prevent recurrence of venous leg ulcers. J Clin Nurs 2010;19:1289-97 https://doi.org/

30 Nelson EA, Bell-Syer SEM. Compression for preventing recurrence of venous ulcers. Cochrane Database Syst Rev 2014;9:CD002303 https://doi.org/

31 Weller CD, Buchbinder R, Johnston RV. Interventions for helping people adhere to compression treatments for venous leg ulceration. Cochrane Database Syst Rev 2016;3:CD008378 https://doi.org/

32 Smith D, Lane R, McGinnes R, et al. What is the effect of exercise on wound healing in patients with venous leg ulcers? A systematic review. Int Wound J 2018;15:441-53 https://doi.org/

33 Jull A, Parag V, Walker N, et al. The prepare pilot RCT of home-based progressive resistance exercises for venous leg ulcers. J Wound Care 2009;18:497-503 https://doi.org/

34 Padberg FT, Johnston MV, Sisto SA. Structured exercise improves calf muscle pump function in chronic venous insufficiency: a randomized trial. J Vasc Surg 2004;39:79-87.

35 Barber GA, Weller CD, Gibson SJ. Effects and associations of nutrition in patients with venous leg ulcers: a systematic review. $J$ Adv Nurs 2018;74:774-87 https://doi.org/

36 Protz K, Dissemond J, Seifert M, et al. Education in people with venous leg ulcers based on a brochure about compression therapy: a quasi-randomised controlled trial. Int Wound J 2019;16:1252-62 https://doi.org/

37 Van Hecke A, Grypdonck M, Beele H, et al. Adherence to leg ulcer lifestyle advice: qualitative and quantitative outcomes associated with a nurse-led intervention. J Clin Nurs 2011;20:429-43 https://doi. org/

38 Kapp S, Miller C, Sayers V, et al. The leg ulcer prevention program: effectiveness of a multimedia client education package for people with venous leg ulcers. Wound Practice \& Research 2010;18:80-90.

39 Heinen M, Borm G, van der Vleuten C, et al. The lively legs selfmanagement programme increased physical activity and reduced wound days in leg ulcer patients: results from a randomized controlled trial. Int J Nurs Stud 2012;49:151-61 https://doi.org/

40 González A. Education project to improve venous stasis selfmanagement knowledge. J Wound Ostomy Continence Nurs 2014;41:556-9 https://doi.org/

41 O'Brien J, Finlayson K, Kerr G, et al. Evaluating the effectiveness of a self-management exercise intervention on wound healing, functional ability and health-related quality of life outcomes in adults with venous leg ulcers: a randomised controlled trial. Int Wound J 2017;14:130-7 https://doi.org/

42 Domingues EAR, Kaizer UAO, Lima MHM. Effectiveness of the strategies of an orientation programme for the lifestyle and woundhealing process in patients with venous ulcer: a randomised controlled trial. Int Wound J 2018;15:798-806 https://doi.org/
43 Shanley E, Moore Z, Patton D, et al. Patient education for preventing recurrence of venous leg ulcers: a systematic review. J Wound Care 2020;29:79-91 https://doi.org/

44 Probst S, Allet L, Depeyre J, et al. A targeted interprofessiona educational intervention to address therapeutic adherence of venous leg ulcer persons (TIEIVLU): study protocol for a randomized controlled trial. Trials 2019;20:243 https://doi.org/

45 Probst S. The Impact of a Pluridisciplinary Education Program on Venous Leg Ulcer Size Reduction (vened) 2019 [Study protocol]. Available: https://clinicaltrials.gov/ct2/show/NCT04019340?term= education\&cond=leg+ulcer\&cntry $=\mathrm{CH} \& d r a w=2 \& r a n k=2$

46 Giordan A, Jacquemet S, Golay A. A new approach for patient education: beyond constructivism. Patient Educ Couns 1999;38:61-7 https://doi.org/

47 Van Hecke A, Verhaeghe S, Grypdonck M, et al. Processes underlying adherence to leg ulcer treatment: a qualitative field study. Int J Nurs Stud 2011;48:145-55 https://doi.org/

48 Holloway I, Galvin K. Qualitative research in nursing and healthcare 4E. John Wiley \& Sons, Inc, 2016.

49 Foley G, Timonen V. Using Grounded theory method to capture and analyze health care experiences. Health Serv Res 2015;50:1195-210 https://doi.org/

50 Singh S, Estefan A. Selecting a Grounded theory approach for nursing research. Glob Qual Nurs Res 2018;5:233339361879957 https://doi.org/

51 Charmaz K. Constructing Grounded theory: a practical guide through qualitative analysis. London; Thousand Oaks, Calif: SAGE Publications Inc, 2006: 224.

52 Charmaz K. Constructing grounded theory. London: SAGE, 2014.

53 Bobbink P, Pugliese M-T, Larkin P, et al. Nurse-led patient education for persons suffering from a venous leg ulcer in outpatient's clinics and homecare settings: A scoping review. J Tissue Viability 2020 https://doi.org/https://doi.org/

54 Dunne $\mathrm{C}$. The place of the literature review in grounded theory research. Int J Soc Res Methodol 2011;14:111-24 https://doi.org/Pii

55 Polit DF, Beck CT. Nursing research 11E (int ED. PB: Lippincott Williams\&Wilki, 2020.

56 Glaser BG, Strauss AL, Press S. The discovery of Grounded theory: strategies for qualitative research. Aldine Publishing Company, 1967.

57 McCrae N, Purssell E. Is it really theoretical? A review of sampling in grounded theory studies in nursing journals. J Adv Nurs 2016;72:2284-93 https://doi.org/

58 Emmel N. Sampling and choosing cases in qualitative research: a realist approach. University of Leeds, UK: SAGE Publications Ltd, 2013.

59 Ward K, Gott M, Hoare K. Participants' views of telephone interviews within a grounded theory study. J Adv Nurs 2015;71:2775-85 https:// doi.org/

60 YARETA. YARETA, The Research Data Repository of Geneva's Higher Education Institutions. Geneva: Higher Education Institutions.

61 corp. I. SPSS statistics for windows. Armonk, NY 2018.

62 Software V. MAXQDA. Berlin: Verbi Software, 2020.

63 Rieger KL. Discriminating among grounded theory approaches. Nurs Inq 2019;26:e12261 https://doi.org/

64 Bøttcher Berthelsen CG-A, Smila SL, Hansen C. Developing a guideline for reporting and evaluating Grounded theory research studies (GUREGT). International Journal of Health Sciences 2018;6:64-76 https://doi.org/ 